\title{
Missing carbon mystery: Case solved?
}

\author{
Scientists claim to have located the 'missing carbon sink' in tropical forests that are absorbing \\ around one billion tonnes more carbon than previously thought. Jane Burgermeister investigates.
}

They looked for it here and they looked for it there, but the carbon had vanished into thin air. So it seemed in the case of the 'missing carbon sink', a billion tonnes of human-generated carbon assumed to be absorbed by northern forests, but unaccounted for in field studies. Scientists now say they have located the missing carbon in tropical forests that are removing much higher quantities of carbon dioxide from the atmosphere than realized.

Of the 8 billion tonnes of carbon that human activity produces each year -6.4 from fossil-fuel emissions, and 1.6 from deforestation, mainly in the tropics ${ }^{1}$ - on average, 3.2 billion tonnes remain in the atmosphere, 2.2 billion tonnes are stored in the oceans and 2.6 billion tonnes are sucked up by land-based carbon sinks, mainly forests. Carbon-uptake models predict that as much as 2.4 billion tonnes of this carbon ends up in northern mid- to high-latitude forests. But scientists searching for it on the ground - measuring trees and carbon exchanges between the vegetation and the atmosphere - have only been able to account for about 0.7 billion tonnes there ${ }^{2}$.

\section{AIRCRAFT ANALYSES}

Researchers led by Britton Stephens from the National Center for Atmospheric Research in Boulder, Colorado in the USA have now found an answer to this mystery. In a paper published in Science $^{3}$, they show that tropical forests are absorbing about one billion tonnes more carbon than previously thought and that northern mid-latitude forests are absorbing 0.9 billion tonnes, or $38 \%$, less than assumed up until now. To test how well models represented carbon sinks, Stephens and his team analysed atmospheric $\mathrm{CO}_{2}$ from aircraft samples collected twice a week at 12 locations worldwide for up to 27 years. They found that $\mathrm{CO}_{2}$ levels in northern latitudes were much greater at high altitudes relative to surface levels than predicted by carbon models. They then compared their observations with predictions of the

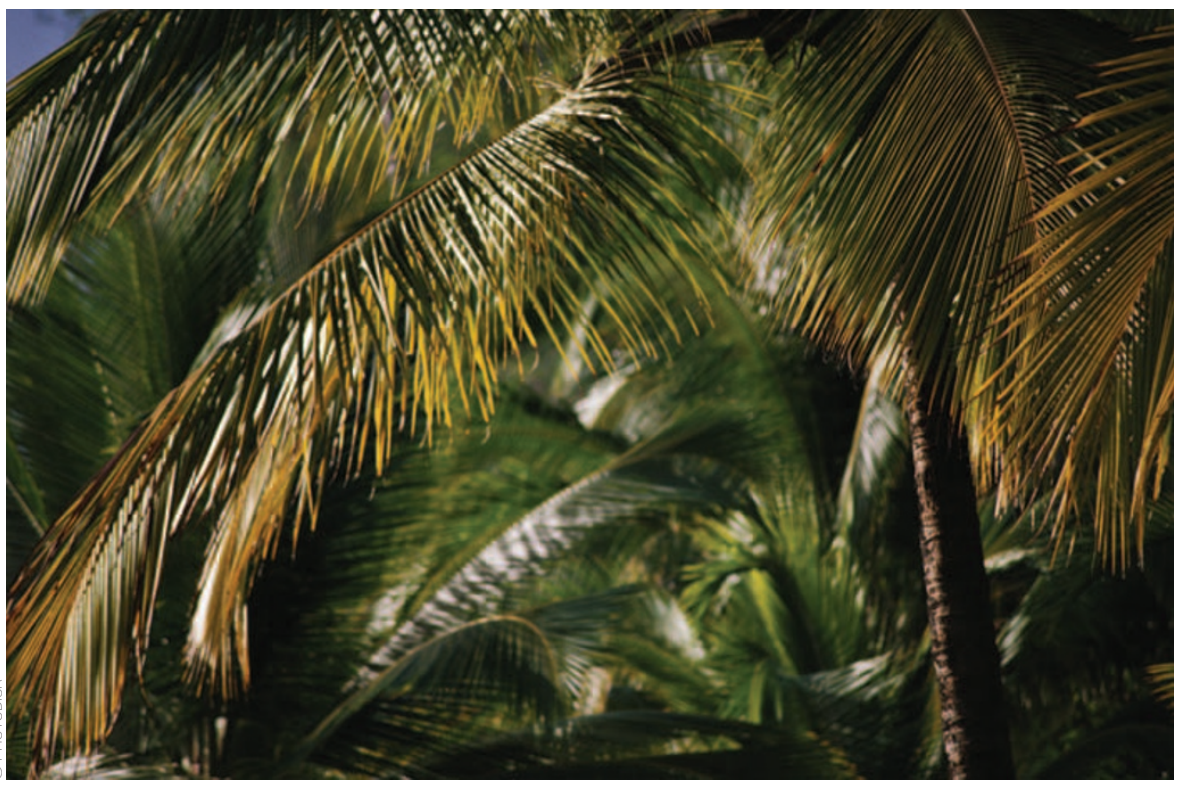

Tropical forests could be absorbing as much as one billion tonnes more carbon than previously realized. vertical gradients in atmospheric $\mathrm{CO}_{2}$ concentrations made by 12 computer models for atmospheric transport. When it came to estimating which forests are the main terrestrial carbon sinks, most conventional carbon uptake models were off target because they did not sufficiently account for vertical mixing of $\mathrm{CO}_{2}$ through the atmosphere as a result of convection and storm systems. Of the 12 , three models accurately represented the measured vertical gradient in $\mathrm{CO}_{2}$ at high altitudes. On average, these three selected models predicted that tropical forests take up much more carbon than previously thought, whereas the opposite was true for forests in the northern latitudes.

\section{Cutting down tropical forests} not only increases carbon emissions but it also removes a strong sink and its potential for offsetting future emissions.

Britton Stephens

\section{EERTILIZATION FACTOR}

Despite rapid deforestation, Stephen's team also showed that tropical forests are the net source of a mere 100 million tonnes of carbon annually, contrary to previous estimates of 1.8 billion tonnes. This suggests that carbon sequestration in the tropics is substantial enough to almost counterbalance the effects of deforestation. Stephens says "tropical forests are essentially in balance, absorbing as much carbon dioxide as they give off". One reason tropical forests could be absorbing substantially more carbon dioxide than accounted for in the models is the phenomenon known as $\mathrm{CO}_{2}$ fertilization. Trees take in carbon dioxide to grow and when there is more of it they tend to grow faster, being fertilized by carbon dioxide. Also, as temperatures increase with climate 


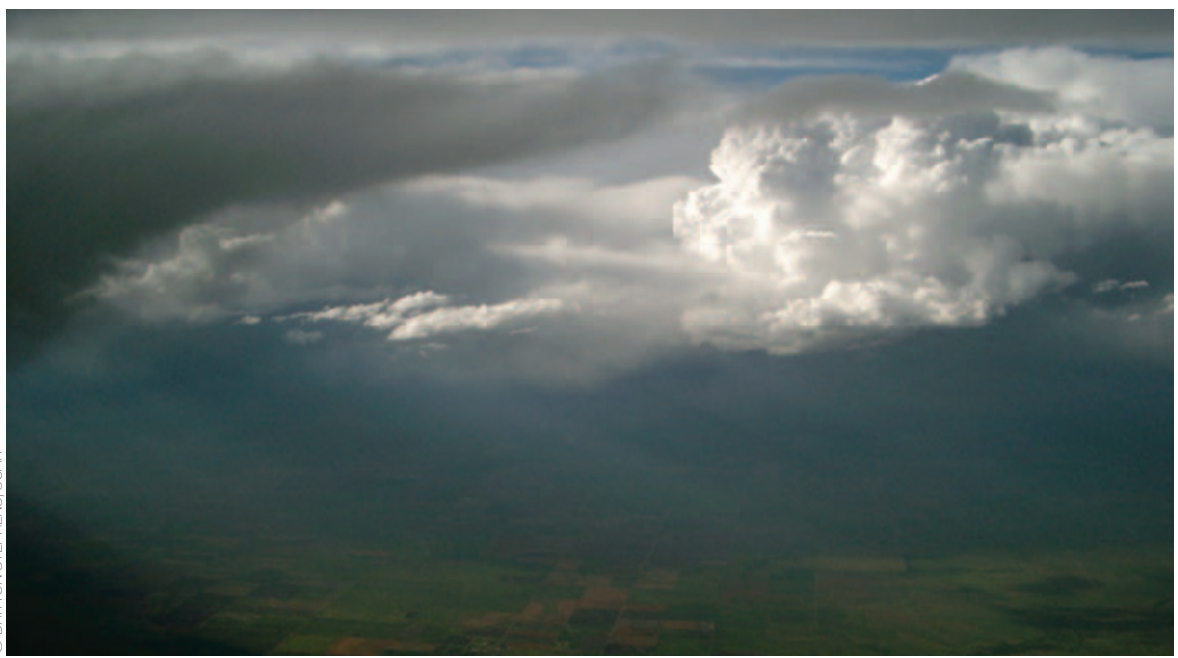

Airborne over Colorado.

change, soil organic matter decomposes more quickly, freeing up nutrients in the ground for forest growth.

Temperate and boreal forests are also being fertilized indirectly by nitrogen, largely from farming and fuel use, according to a study recently published a study in Nature ${ }^{4}$, led by Federico Magnani from the University of Bologna. The study suggests that this is contributing to the carbon sink in northern latitudes, but Magnani says the same could not be true for tropical forests, where phosphorous and not nitrogen determines growth. He says that to understand what is happening in the tropics "we need to know how much of the carbon sink is the result of vegetation regrowth following deforestation, and how much of it comes from substantial carbon sequestration by primary forests". Manuel Gloor of the University of Leeds, UK, also argues that we need more information before any assertions on the whereabouts of the missing carbon sink can be confirmed. "To really settle the question regarding tropical versus northern hemisphere carbon sinks, a substantial amount of atmospheric concentration data over tropical land will be needed", he says.

\section{ALBEDO EFFECT}

Other scientists have also recently come to the conclusion that northern forests, although critically important in maintaining biodiversity, might be less important in slowing climate change than tropical forests. Govindasamy Bala and Ken Caldeira found that tropical forests help cool the Earth in two ways: by storing carbon and also by reflecting the suns warming rays back to space ${ }^{5}$. "Unlike tropical forests, high latitude forests darken the Earth's surface, causing

the earth to absorb more sunlight, an effect that is most pronounced in snowy regions. This darkening of the surface has a warming influence that can be stronger than the cooling influence of carbon storage in these forests," says Caldeira. This suggests that removing high-latitude forests would have a net cooling effect on the planet, whereas removal of tropical forests would result in warming.

\section{ULTIMATELY ACADEMIC?}

Tropical forests are, however, rapidly disappearing. Forests in South America, Central Africa and South-East Asia are being cleared for cropland or cattle pasture, and reduced by the expansion of logging

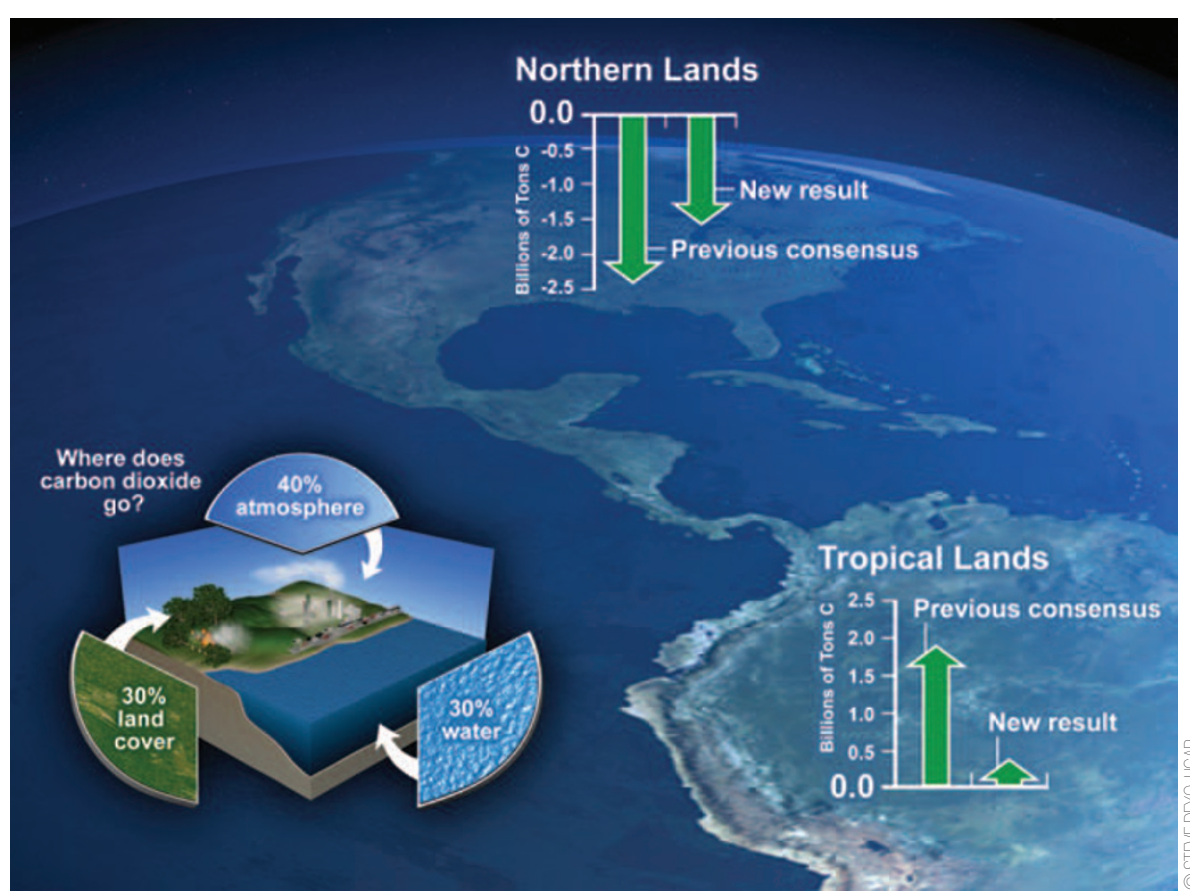

Locating the 'missing carbon sink' in the tropics has implications for the entire global carbon cycle.

and changing patterns of cultivation. The latest IPCC report on mitigating climate change $^{6}$ found that during 2004, the contribution of deforestation - primarily in the tropics - and the decay of biomass to global warming was $17.3 \%$ of total global greenhouse-gas emissions. "Cutting down tropical forests not only increases carbon emissions but it also removes a strong sink and its potential for offsetting future emissions," says Stephens.

Whether tropical or northern forests store more carbon might ultimately be academic, though, when it comes to mitigating climate change. Stephens believes that "relying on trees to mitigate climate change is not a good long-term strategy, because the carbon they store gets returned to the atmosphere on a timescale of around 30 years when they die and decompose. Afforestation and reforestation can provide short-term sinks to slow warming and possibly give us more time to find solutions, but ultimately we need to get the carbon into the ocean or geologic reservoirs, or not emit it in the first place".

\section{Jane Burgermeister is a freelance} science writer.

\section{REFERENCES}

1. Steffen, W. et al. Science 280, 1393-1394 (1998).

2. Goodale, C. L. et al. Ecol. Appl. 12, 891-899 (2002).

3. Stephens, B. et al. Science 316, 1732-1735 (2007)

4. Magnani, F. et al. Nature 447, 848-850 (2007).

5. Bala, K. et al. Proc. Natl Acad. Sci. USA 104, 6550-6555 (2007).

6. Working Group III Report: Mitigation of Climate Change

(Intergovernmental Panel on Climate Change, 2007); http:// arch.rivm.nl/env/int/ipcc/pages_media/AR4-chapters.html 